\title{
A Hydrostatic Pressure-Driven Desalination System for Large-Scale Deep Sea Space Station
}

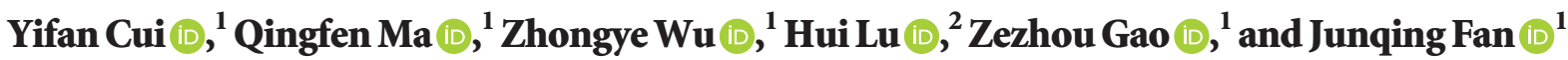 \\ ${ }^{1}$ College of Mechanical and Electrical Engineering, Hainan University, Haikou, Hainan 570228, China \\ ${ }^{2}$ Institute of Environment and Plant Protection, Chinese Academy of Tropical Agriculture Sciences, Haikou, \\ Hainan 571101, China \\ Correspondence should be addressed to Qingfen Ma; mqf0920@hainanu.edu.cn
}

Received 21 September 2020; Accepted 15 January 2021; Published 27 January 2021

Academic Editor: Maksim Mezhericher

Copyright (C) 2021 Yifan Cui et al. This is an open access article distributed under the Creative Commons Attribution License, which permits unrestricted use, distribution, and reproduction in any medium, provided the original work is properly cited.

Compared with the common marine renewable energy sources like solar, wind, and wave energy, etc., the hydraulic pressure stored in the deep seawater can output stable and successive energy flow. Thus, it can be directly coupled with the reverse osmosis (RO) process to supply drinkable mineral water for crews of Deep Sea Space Station (DSSS). We proposed a novel submarine RO desalination system driven by the hydraulic pressure of deep seawater (SHP-RO), composed of a desalination branch to generate fresh water and a back pressure branch to ensure the depth independence of the desalination. The influences of the deep sea environment on the RO were analyzed, based on which the pretreatment of the seawater and the preparation of the drinkable mineral water were studied. The turbine-based energy recovery scheme was investigated in virtue of the CFD simulation on the flow behavior in the different turbine series. It was predicted that, when the DSSS was located at the depth of $1100 \mathrm{~m}$ and the operating pressure of the RO process was $6.0 \mathrm{MPa}$, for a drinkable water production rate of $240 \mathrm{~m}^{3} / \mathrm{d}$, the recovered hydraulic pressure energy can achieve $39.22 \mathrm{~kW} \cdot \mathrm{h}$, which was enough for driving electricity consumers in the SHP-RO system.

\section{Introduction}

The United Nations proposed guaranteeing a sustainable supply of high-quality fresh water to the world [1], since fresh water supply, one of the most important bases of human survival and social development, is faced with increasing challenge due to the population expansion, industrialization, and various pollutions, etc. The method of obtaining sufficient fresh water by desalination is generally accepted by most people, especially in some areas short of water and located in coast area $[1,2]$. At present, multistage flash (MSF) and reverse osmosis (RO) are primarily adopted, occupying over $85 \%$ of current desalinated water production [3]. Other kinds of desalination technologies were also explored with different principles, such as multieffect distillation (MED) [4], electrodialysis (ED) [4], forward osmosis (FO) [5], membrane distillation (MD) [4], humidification-dehumidification $(\mathrm{HDH})$ [4], capacitance deionization (CDI) [6], gas hydrates (GH) [6], and freezing [6].
The most primary energy sources of the above desalination techniques are the fossil fuel which conflicts with the sustainable development and the environment protection. Therefore, renewable energy sources like solar energy, wind energy, tidal energy, wave energy, and temperature-difference energy become much attractive to drive the seawater desalination, with great development prospect and being tested widely $[1,2,5,7-11]$. The statistics suggested that the solar-powered desalination systems have occupied $32 \%$ of the renewable energy desalination field and the windpowered desalination schemes accounted for 19\% [12]. The combination of renewable energy with seawater desalination system brings great challenges to conventional desalination system. The intermittence and volatility of wind and solar energy especially cause a series of problems such as the change of system power or even interruptions which will do damage to the equipment and greatly reduce the service life of the equipment $[12,13]$. In addition, the low energy density of the above common renewable energy results in bulky conversion equipment which will restrict the application of 
the renewable-energy driven desalination plant on offshore facilities, small islands, or ships.

In the open sea, the depth of seawater easily reaches hundreds of meters and the hydrostatic pressure energy of seawater at the depth of 500-800 m can be reasonably utilized to drive desalination replacing the above renewable energy, with stable and successive energy flow. Up to now, most of the related literatures were about the conceptual design and theoretical analyses, and three conceptual schemes were proposed for hydrostatic pressure driven RO desalination, i.e., the submarine desalination plants, underground plants, and mountain-foot plants [14]. In the submarine desalination plants, the devices are set submarine at a depth of $500-800 \mathrm{~m}$, and driven pressure for $\mathrm{RO}$ is obtained by the pressure difference between the hydrostatic pressure and atmospheric pressure. The produced fresh water is collected in a storage tank and then pumped to the sea level, and the brine is discharged into the sea [15-17]. In the underground plants, devices are placed at about $500 \mathrm{~m}$ underground. The RO modules are at atmospheric pressure and the seawater is pumped and then pushed into the $\mathrm{RO}$ module by hydrostatic pressure. The fresh water is collected into the tank and pumped to the land and the brine is discharged though pipes to the deep sea [18]. In the mountain-foot plants, a storage tank and the membrane module are placed at the top and the foot of the mountain, respectively, and connected with flexible pipe. Then, the pressure generated by water column was used to drive the $\mathrm{RO}$ desalination. The fresh water is collected in the tank on the land and the brine is discharged into the sea [19].

The submarine desalination plant is suited for the distant sea application, and the energy consumption is competitive with minimal consumption of the commercial RO plant. It was predicted that, when the recovery rate is $25 \%$ and the water production is $2 \times 10^{4} \mathrm{~m}^{3} /$ day, the theoretical energy consumption of the system was $2.98 \mathrm{kWh} / \mathrm{m}^{3}$, about $64 \%$ of which was caused by the fresh water pumping from the deep sea to surface [14]. However, if the desalinated water has to be pumped to the surface for utilization, the submarine desalination technique becomes less attractive, for the main body of the device has to immersed in seawater with depth of 400-600 m, bringing about a series of technical difficulties in design and operation, such as coupling difficulty between offshore platform and undersea devices and pipes, installation and maintenance difficulties, etc., which will also cause more capital cost and operating cost than the traditional RO plant.

With the increasing human exploration of the distant and deep sea, Deep Sea Space Station (DSSS) will become a commonly used carrier for human activity in which fresh water supply is necessary especially for the long-term stay. For this demand, the submarine desalination plant driven by the hydraulic water pressure is a perfect solution for fresh water supply, since it does not consume any conventional energy and can utilize the plenty seawater and its hydraulic energy stably without fluctuation and intermittence which are inherent in other renewable energy sources.

So far, the only undersea laboratory in the world mentioned by NASA, Aquarius, is located in shallow water about 60 feet below sea level [20]. Its internal environmental pressure is equal to the external pressure, both of which are higher than atmospheric pressure. Aquarius was founded for the study of the ocean and the training of astronauts, but not for the human activities of deep sea exploration.

The DSSS described in this paper is a concept design of a future device which is a carrier for human deep sea exploration and usually located in the deep sea below $500 \mathrm{~m}$. DSSS can be used as a transit or research base station for ocean exploration and development of marine resources, a new platform for submarine sightseeing, and a military base station for regional surveillance, submarine defense, and submarine strike. Besides, DSSS will provide opportunities for people to survive submarines if the land and climatic environment are disturbed or destroyed by some irresistible factors.

For the DSSS, the external pressure is much higher than that of the internal environment which is suitable for human living. In order to ensure the normal activities of human beings in the DSSS, it is necessary to provide fresh water, energy, and oxygen. Fresh water can be obtained from the seawater desalination, energy can be converted from the renewable energies such as the ocean thermal energy and tidal current energy, and oxygen can be produced by electrolyzing fresh water with the byproduct hydrogen as another energy source for DSSS.

In this paper, we focused on how to supply the fresh water for DSSS from the deep seawater utilizing the pressure difference between the outside and inside of DSSS, without consuming any conventional energy source. We proposed a novel submarine $\mathrm{RO}$ desalination process driven by the hydraulic pressure of seawater (SHP-RO) to generate drinkable mineral water for the large- and small-scale DSSS from nutritive deep seawater. The SHP-RO consists of the pretreatment unit, RO modules, the constant differential pressure device, pressure relief system (for small-scale DSSS) or energy recovery system (for large-scale DSSS), mineral water mixer, seawater pumps and necessary pipes, valves and control elements, etc. Driven by deep sea hydrostatic pressure and assisted by pumps, seawater can be continuously transported to the RO modules after necessary pretreatment, and then partial water permeates through the membrane due to the pressure difference between two sides of RO membrane. Compared with the mentioned desalination devices driven by hydrostatic pressure, it is unnecessary to keep the working depth of the DSSS within the range of 400-600 $\mathrm{m}$, for the pressure difference between the two sides of the RO membrane can be maintained at a designed value by a constant differential pressure device, ensuring the RO process to go on wheels in much deeper sea where the DSSS needs to arrive. Considering the safety of water use and the recovery of hydrostatic pressure energy, pressure relief valve and energy recovery device are applied in the desalination system for the small- and large-scale DSSS, respectively. In Section 2, the working process and principles of the SHP-RO for drinkable mineral water production of large- and small-scale DSSS are introduced. In Section 3, key components and parameters of the process are analyzed including the RO membrane and modules, 
pretreatment unit, and preparation of the drinkable mineral water. In Section 4, the energy recovery system for the largescale DSSS is designed and analyzed based on the CFD simulation.

\section{Working Process and Principles of the SHP-RO}

Deep seawater is far away from the influence of human daily activities and is not polluted by land, atmospheric chemicals, and environmental hormones. Moreover, sunlight is hard to reach so there are very few bacteria and other pathogens. It also contains several minerals and microelements which the human body needs in daily life. Therefore, the drinkable mineral water, a blend of the deep seawater and its desalinating product, is expected to be healthy for human life. Deep seawater contains various beneficial mineral ions and it has the preventive effect on hepatic steatosis disease caused by high-fat diet and atherosclerosis [21, 22]. It may also improve cardiovascular hemodynamics and have the potential as an effective substance for diabetes, hypercholesterolemia, and atopic dermatitis [23-28].

The SHP-RO system proposed in this paper can be applied to both large-scale and small-scale DSSS. It is designed to generate the mineral drinkable water for the crews of the DSSS from the nutritious and clean deep seawater using the abundant and stable hydraulic pressure energy hidden in the deep ocean environment.

The submarine desalination device driven by hydraulic pressure of deep seawater in Figure 1 is suitable for the largescale DSSS which works under seawater with depth more than $500 \mathrm{~m}$. The deep seawater is driven by its high hydraulic pressure and partially forced through the RO membrane going into the fresh water tank with much lower pressure. The commercial RO membrane module includes spiral coil, plate, tube, and hollow fiber, among which the spiral coil type is used most widely due to its large membrane area. Therefore, in SHP-RO system the spiral coil type is determined as the RO membrane module.

Since the working pressure required for RO desalination is about $5.0-8.0 \mathrm{MPa}$, when the depth of the DSSS is greater than $800 \mathrm{~m}$, it is necessary to increase the back pressure of RO membrane correspondingly to maintain the reasonable pressure difference between the two sides of RO membrane. For this consideration, an assisted back pressure branch mainly including a constant pressure relief device, a back pressure generator, and several pressure dissipating devices is designed and starts working when the DSSS depth is greater than $800 \mathrm{~m}$. Pressure relief valve and energy consumption device are set in the seawater branch. After high-pressure seawater passes through the pressure relief valve, part of ocean water enters seawater container to stabilize the pressure for RO desalination process, and the other part is further depressurized through the energy dissipation device until the pressure is reduced to a safe range. To recover the residual hydraulic energy of desalinated water and avoid its shock and damage to the system, several turbines are set in freshwater branch. The desalinated and depressurized fresh water is finally collected in the DSSS water tank at atmospheric pressure, and mixed with the deep seawater from the pressure valve and necessary energy dissipation devices at a set proportion to generate the mineral drinkable water.

The SHP-RO desalination device for small-scale DSSS is broadly similar to that used in the large scale, except that there is no need to equip energy recovery turbines due to the smaller water demand and light-weight requirement to realize the flexibility in motion. Thus, the residual hydraulic energy stored in both the desalinated water and the pressureadjusting seawater is all dissipated by the energy consuming device such as pressure relief valves.

\section{Parameter Design and Performance Analysis of Water Production}

3.1. Influence of Deep Ocean Environment on the Performance of RO Membrane. The SHP-RO device works in deep ocean environment, and the temperature of seawater satisfies the law of vertical distribution. The deep ocean is less affected by the conduction and convection of solar radiation and surface heat, so the temperature decreases with the depth. The vertical profile of ocean temperature is shown in Figure 2. Generally, the vertical structure of ocean includes mixed layer, thermocline, and deep layer according to temperature variation, and the thermocline is normally between the depths of $200 \mathrm{~m}$ to $1000 \mathrm{~m}$. The seawater temperature in the mixed layer is approximately the same as that on the surface; the seawater temperature distribution in the thermocline and deep layer can be expressed by a linear and a nonlinear equation, respectively. Based on Argo profile data of Indian Ocean in July, the attenuation of temperature with depth $h$ can be expressed by equation (1) [29, 30].

$$
\left\{\begin{array}{l}
T(z)=T_{\mathrm{s}}, \quad 0 \leq h \leq h_{1}, \\
T(z)=T_{\mathrm{s}}+G_{\mathrm{th}}\left(h-h_{1}\right), \quad h_{1}<h \leq h_{2}, \\
T(z)=c_{1} \exp \left(c_{2} h\right)+c_{3} \exp \left(c_{4} h\right), \quad h>h_{2},
\end{array}\right.
$$

where $G_{\text {th }}\left({ }^{\circ} \mathrm{C} \cdot \mathrm{m}^{-1}\right)$ is the thermocline strength; $c_{1}, c_{2}, c_{3}$, and $c_{4}$ are the fitting coefficients of nonlinear curve; and $T_{\mathrm{s}}\left({ }^{\circ} \mathrm{C}\right)$ is the surface temperature of the ocean.

The permeate flux of RO membrane is sensitive to the temperature of feed water, deceasing when the temperature declines. The reason is that the viscosity of water molecules rises with the decrease of temperature, leading to the decrease of diffusion abilities. The relationship between temperature and membrane flux can be expressed by equation (2), where $J\left(\mathrm{~L} \cdot \mathrm{m}^{-2} \cdot \mathrm{h}^{-1}\right)$ represents the membrane flux at seawater temperature $T\left({ }^{\circ} \mathrm{C}\right)$ and $J_{0}\left(\mathrm{~L} \cdot \mathrm{m}^{-2} \cdot \mathrm{h}^{-1}\right)$ represents membrane flux under standard testing conditions.

$$
J(T)=J_{0} \times 1.03^{T-25} \text {. }
$$

Combining equations (1) and (2), the membrane flux can be expressed as a function of the ocean depth as shown in equation (3).

$$
\left\{\begin{array}{l}
J=J_{0} \times 1.03^{T_{\mathrm{s}}-25}, \quad 0 \leq h \leq h_{1}, \\
J=J_{0} \times 1.03^{T_{\mathrm{s}}+G_{\mathrm{th}}\left(h-h_{1}\right)-25}, \quad h_{1}<h \leq h_{2}, \\
J=J_{0} \times 1.03^{c_{1} \exp \left(c_{2} h\right)+c_{3} \exp \left(c_{4} h\right)-25, \quad h>h_{2} .} .
\end{array}\right.
$$




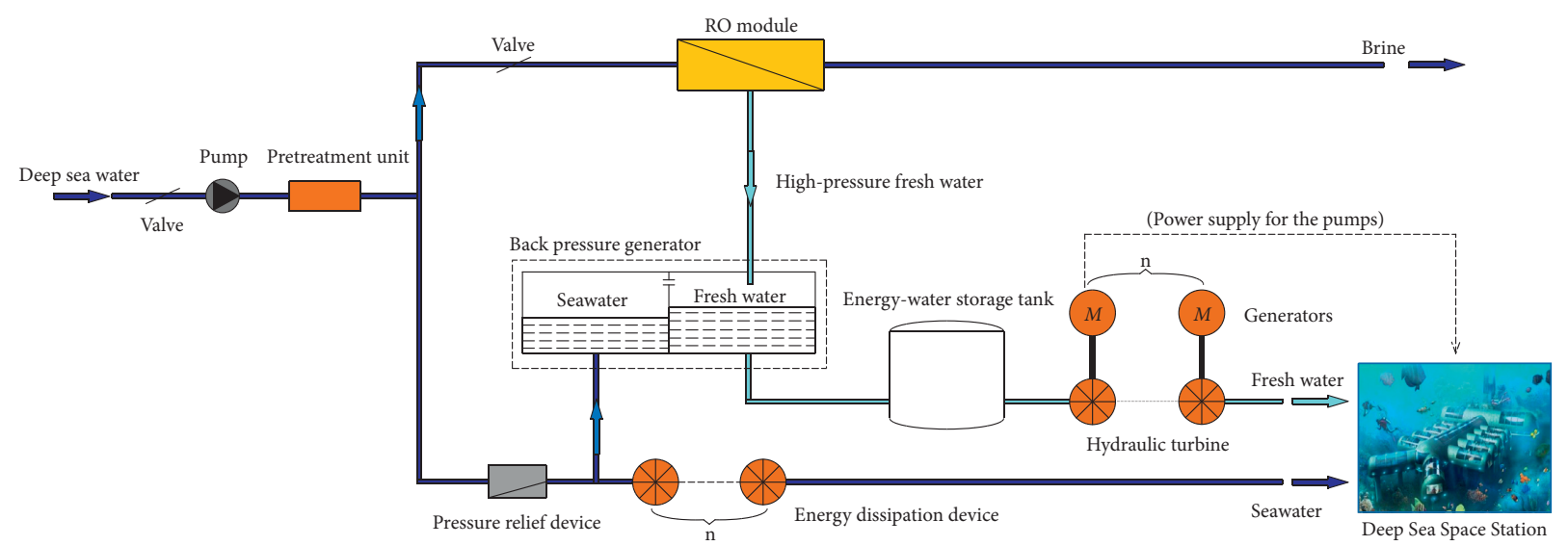

Figure 1: Flow chart of SHP-RO desalination system for large-scale DSSS.

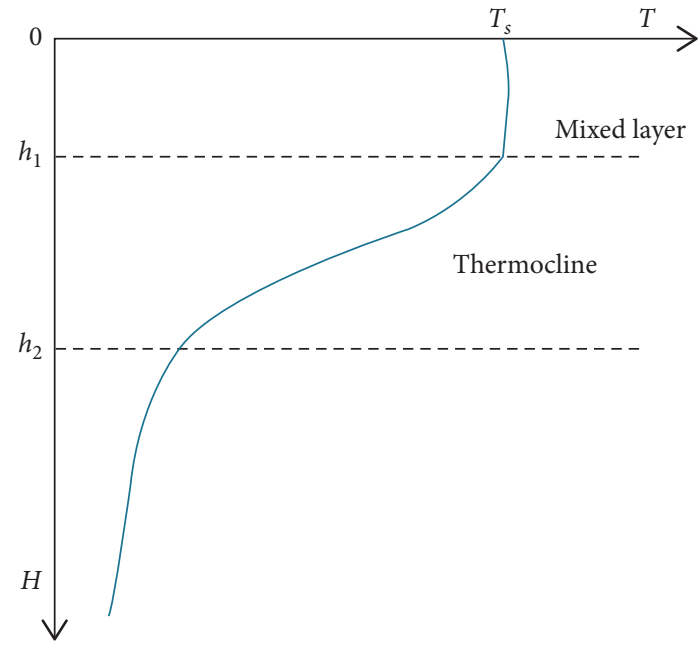

FIgURE 2: Vertical profile of ocean temperature.

According to equation (3), given the RO membrane model and water demand, the membrane flux and the required membrane area can be determined as function of the ocean depth too. Figure 3 shows the variation of membrane flux and membrane area with ocean depth, in which RO membrane of SWC series of HYDECANME (membrane flux at the pressure of $5.5 \mathrm{MPa}$ is about $\left.0.05 \mathrm{~m}^{3} \cdot \mathrm{m}^{-2} \cdot \mathrm{h}^{-1}\right)$ was adopted, and the water yield of $10 \mathrm{~m}^{3} / \mathrm{h}$ was regarded as the standard for calculation and analysis. The vertical distribution of the membrane flux with depth exhibits a similar tend to that of seawater temperature, and correspondingly, the membrane area exhibits the opposite. The membrane flux loss caused by depth increase achieves about $50 \%$ and then comes near to depth independent; i.e., we can implement the membrane loss by doubling the membrane area in the deep ocean environment.

If the DSSS is near to or combined with an Ocean Thermal Energy Conversion (OTEC) platform, the feed deep seawater can be first preheated by the warm discharge of the OTEC and then forced to pass through the RO membrane, effectively increasing the membrane flux and decreasing the membrane area. Through this combination, the OTEC and the deep sea hydraulic pressure energy can be used to full advantages, and the water production rate can be effectively

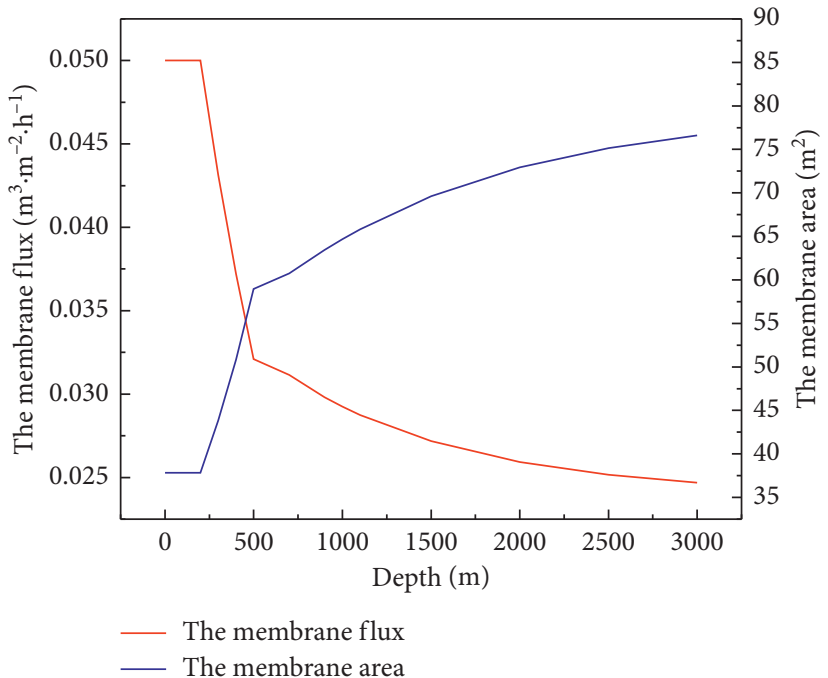

Figure 3: Relationship between depth, membrane flux, and membrane area.

improved including the water yield not only from RO system but also from the flash evaporation.

Besides, the membrane flux loss can also be compensated by increasing the pressure difference between two sides of the RO membrane when the DSSS locates at enough depth, due to the positive correlation between membrane flux and operating pressure. According to relative research [31], we obtained the fitting equation (4) of the membrane flux about the operating pressure difference at $6^{\circ} \mathrm{C}$, with the salt concentration of $3.5 \%$. When the operating pressure difference increases from $5 \mathrm{MPa}$ to $9 \mathrm{MPa}$, the membrane flux can be increased by $52.7 \%$.

$$
J=c_{5} \Delta P+c_{6}
$$

where $\triangle P(\mathrm{MPa})$ is pressure difference and $c_{5}$ and $c_{6}$ are the fitting coefficients.

\subsection{Pretreatment of Deep Seawater for RO Desalination.} Even though deep seawater is clean and lacks bacteria and other pathogens, pretreatment is also necessary to remove 
possible suspended solids, microorganisms, colloidal particles, and large particles in seawater, and prevent the precipitation of metal oxides and microsoluble salts. To avoid the pollution to the deep sea environment, and considering the clean characteristics of deep seawater, a series of membrane modules are employed to replace the addition of chemical reagents.

An optional combination of pretreatment devices is shown in Figure 4, which includes rough filter, microfilter (MF), ultrafilter (UF), and security filter. In the rough filter, the feed water experiences sand filtration and activated carbon filtration. The aim of sand filtration is to separate the impurities from the water through the sand layer. Activated carbon filtration refers to the removal of insoluble substances in deep seawater by adsorption of activated carbon. In addition, activated carbon can also absorb some impurities dissolved in seawater to remove odor. MF and UF refer to the separation of liquid through membrane under the action of pressure difference. MF is used for turbidity reduction and sterilization of liquid medium. UF is used to remove low molecular weight solutes, organic macromolecules, viruses, pathogens, and other substances. The last component of pretreatment is the security filter, also known as the precision filter, which is used to prevent the fine particles from entering the RO membrane module, damaging membrane structure and affecting the service life of membrane. The filtration loss during all the above pretreatment module can be calculated by Darcy formula assuming the seawater as incompressible viscous fluid.

3.3. Generation of Necessary Pressure Difference to Drive RO Desalination. To generate necessary and reasonable pressure difference before and after RO membrane, an assisted back pressure branch is designed, in which the function is implemented by a constant pressure relief device and a back pressure generator. The constant pressure relief device is designed to create a constant pressure drop $\Delta p$ to the deep seawater. The structure of the constant pressure relief device is schematically shown in Figure 5. In the initial conditions, the device is in a static state. When deep seawater with pressure of $p_{1}$ enters the inlet, the piston moves towards outlet under the action of seawater thrust $F_{1}$. In this process, piston moves through holes $A$ on the smooth wall surface, and the deformation of springs is $\Delta L$, which produces the force $F_{k}$. In order to reduce the resistance of seawater flow, holes $A$ are designed as oblique outlets with annular distribution. The seawater flows out of holes $A$ and then into cavity $B$, which acts on the piston and produces a reverse force $F_{2}$. Under the action of $F_{1}, F_{k}$, and $F_{2}$, the piston is in equilibrium, and the pressure difference of the inlet and outlet can be predicted by equation (5). The cylindrical wall of cavity $B$ is designed as a rough surface to prevent the further movement of piston, so that springs deformation is kept at $\Delta L$ to complete a constant pressure drop of seawater. After decompression, the seawater flows out of the outlet and enters the back pressure generator:

$$
p_{1}-p_{2}=\frac{k \cdot \Delta x}{(\pi / 4) \cdot D^{2}}
$$

where $k(\mathrm{~N} / \mathrm{m})$ is stiffness coefficient; $\Delta x(\mathrm{~m})$ is the compression length of the spring; and $D(\mathrm{~m})$ is the diameter of valve core.

The back pressure generator consists of a couple of interconnected seawater container and fresh water container as shown in Figure 1. In the initial state, fresh water is injected into the fresh water container and air with atmospheric pressure is filled into the seawater container so that the pressure in both containers is atmospheric pressure $(0.1 \mathrm{MPa})$. When the working depth of the DSSS is less than $800 \mathrm{~m}$, i.e., the outside hydraulic pressure is less than $8.0 \mathrm{MPa}$, the back pressure branch keeps closed and does not work. Only when the working depth is greater than $800 \mathrm{~m}$ does the back pressure branch open and the devices start to work. Open the valve and direct a small stream of high-pressure seawater to go through the constant pressure relief device, after which the water pressure drop achieves a set value like $8 \mathrm{MPa}$. Then, a part of the seawater flows into the seawater container and compresses the air in seawater container causing the pressure being increased gradually to that of seawater. For the air can freely flow through the top hole which connects seawater and fresh water containers and keeps above the liquid surface, the pressure in the fresh water container is always equal to that of the seawater container. The fresh water outlet pipe of $\mathrm{RO}$ module is connected to the fresh water container of back pressure generator. Hence, the pressure difference before and after RO membrane can be maintained with the help of the back pressure, and the desalination can operate properly.

3.4. Preparation of Drinkable Mineral Water. Both the fresh water and the mineral water produced by SHP-RO system can be directly supplied to the DSSS for drinking. Compared with the fresh water, the mineral water is preferred for it is rich in mineral and trace elements from the clean and nutritious deep seawater. As mentioned, the drinkable mineral water produced by SHP-RO is a mixture of the desalinated water and minute quantity of the pretreated deep seawater. According to the relevant data [32], the most mineral ions in the deep seawater are $\mathrm{Na}^{+}, \mathrm{Mg}^{2+}, \mathrm{Ca}^{2+}, \mathrm{SO}_{4}{ }^{2-}, \mathrm{NO}_{3}{ }^{-}$, and $\mathrm{Cl}^{-}$ in sequence at a depth of $1000 \mathrm{~m}$. Their concentrations, compared with their upper limits specified in standard for drinking water by WHO, are shown in Table $1 . \mathrm{Cl}^{-}$is finally determined as the calculation standard, and the ratio of deep seawater and desalinated water should not be less than 1:76 for the production of deep sea drinkable mineral water.

\section{Energy Recovery of the Desalinated Water}

To recover the residual hydraulic energy of desalinated water and avoid its shock and damage to the system, several turbines are set in freshwater branch. After the energy-water storage tank is full of fresh water, the discharge valve opens to allow water flow through several turbines and recover the residual hydraulic energy stored in the fresh water, and then to be collected in the DSSS water tank with atmospheric pressure. Considering the pressure and flow conditions of the desalinated water, Francis turbine with extensive application is selected as the energy recovery turbine. 


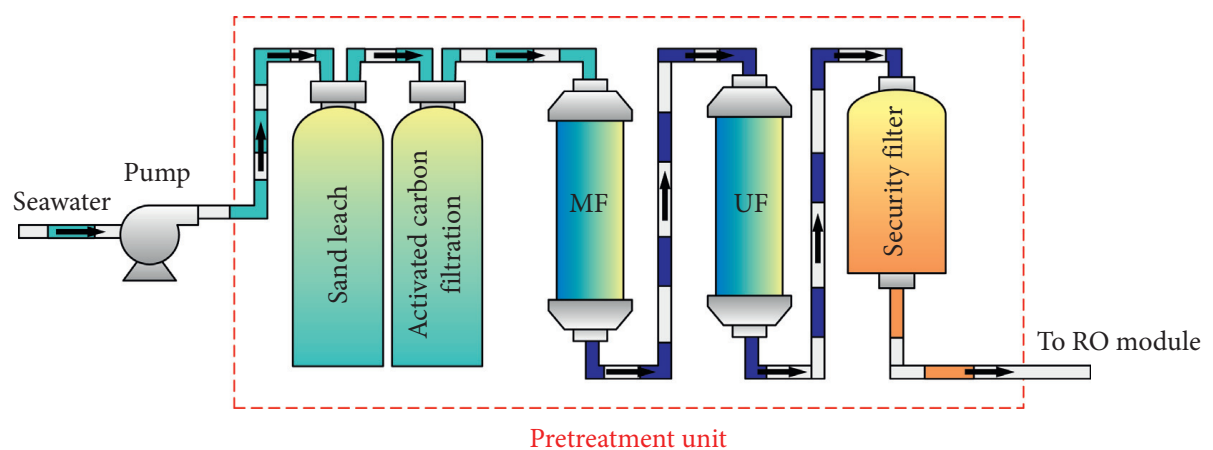

Figure 4: Pretreatment combination of RO desalination.

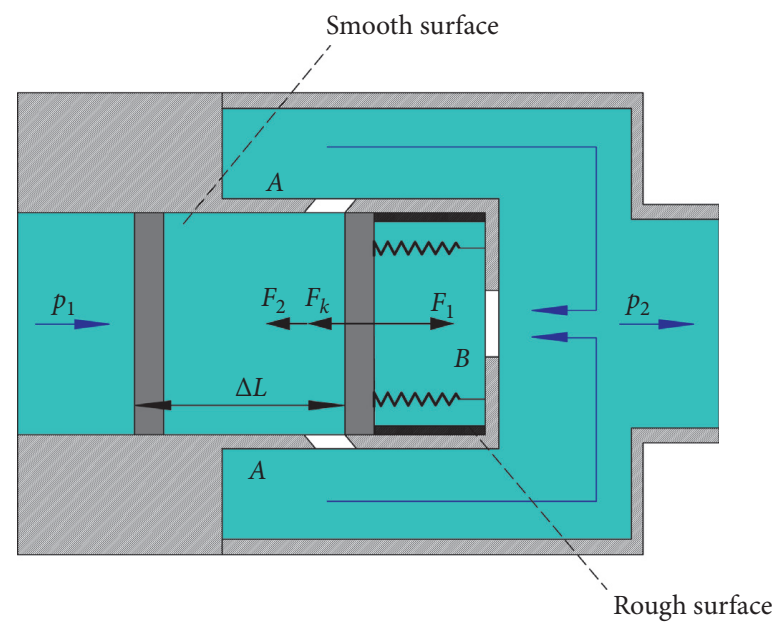

FIGURE 5: Structure diagram of constant pressure reducing valve.

TABLE 1: Concentration of major ions contained in deep seawater at depth of $1000 \mathrm{~m}$ and their upper limits specified in standard for drinking water by WHO.

\begin{tabular}{lcc}
\hline Ions & $\begin{array}{c}\text { Concentration at } 1000 \mathrm{~m} \\
\text { depth }(\mathrm{mg} / \mathrm{L})\end{array}$ & $\begin{array}{c}\text { Upper limits specified } \\
\text { by } \mathrm{WHO}(\mathrm{mg} / \mathrm{L})\end{array}$ \\
\hline $\mathrm{Na}^{+}$ & 11755.81 & 200 \\
$\mathrm{Mg}^{2+}$ & 1390.88 & 20 \\
$\mathrm{Ca}^{2+}$ & 422.61 & 50 \\
$\mathrm{SO}_{4}{ }^{2-}$ & 2540.56 & 250 \\
$\mathrm{NO}_{3}{ }^{-}$ & 6.32 & 50 \\
$\mathrm{Cl}^{-}$(chloride) & 18851.19 & 250 \\
\hline
\end{tabular}

When the fresh water flows through the turbine, blades fixed on the runner rotate due to the impact of water, and then the spindle of the generator connected with the turbine is also driven to rotate to achieve the energy conversion. Pressure energy in fresh water is converted into electric energy which can be stored in batteries, and supplied to the pumps and control modules in the system. In the process of decompression and power generation, multistage tandem Francis turbines can be adopted due to their flexibility, since the operating stage number can be adjusted with recovered pressure. In this section, the energy recovery performance of different series mode of Francis turbines is investigated in virtue of the CFD simulation, aiming to obtain an effective turbine-based method to recover the residual pressure energy contained in the desalinated water of SHP-RO.
4.1. Geometric Model of Francis Turbine. The Francis turbine is composed of diversion, guide, working, and drainage component, with the major parameters as follows: the diameter of the runner and volute inlet is $500 \mathrm{~mm}$ and $772 \mathrm{~mm}$, respectively; the number of blades, active guide vanes, and fixed guide vanes is 13,18 , and 11 , respectively. Figure 6 shows the 3D models of characterized components or fluid domains in the Francis turbine. The volute and guide vanes are cooperated to guide the water flow and thus are integrated together in the model shown in Figure 6(a). Runner is the key component to convert hydraulic energy into mechanical energy. As shown in Figure 6(c), it is mainly composed of crown, band, and blades which is generally designed as a three-dimensional curved surface according to hydraulics shown in Figure 6(b). In practical application, the 


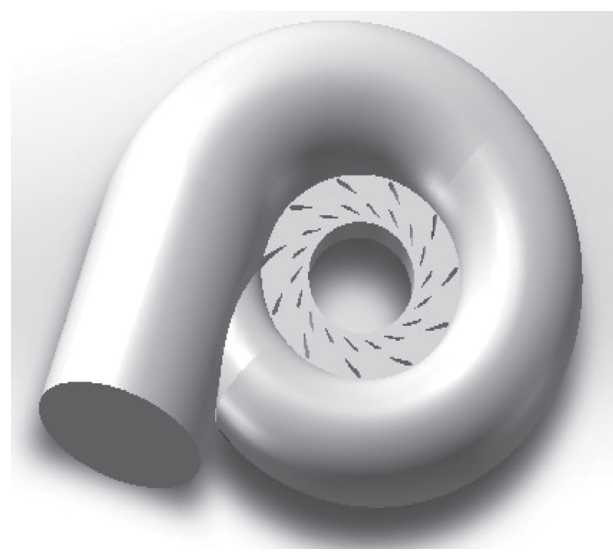

(a)

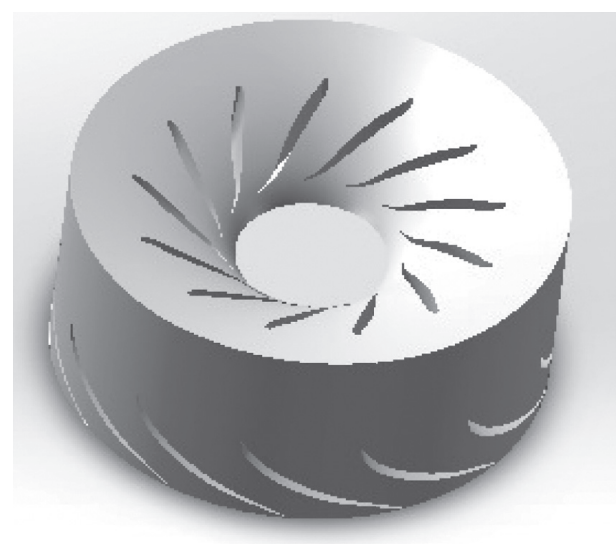

(c)

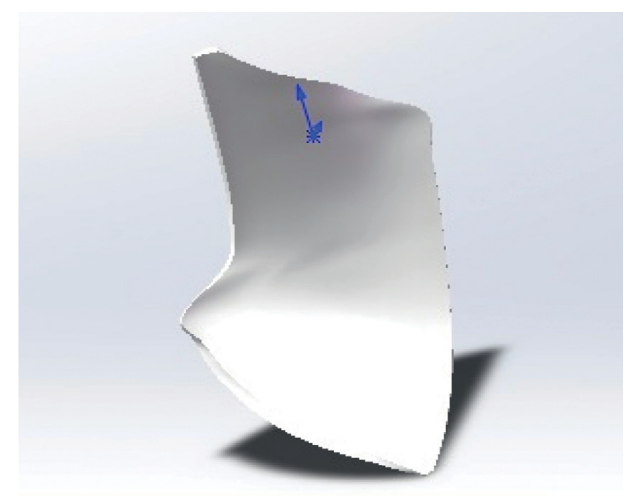

(b)

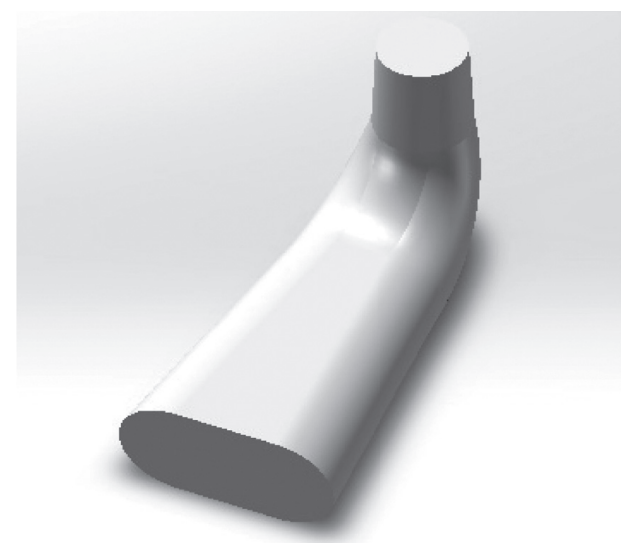

(d)

Figure 6: 3D models of characterized components or fluid domains in the Francis turbine. (a) Fluid domain of the volute and guide vanes; (b) blade model; (c) fluid domain of runner; (d) fluid domain model of draft tube.

draft tube of hydraulic turbine should be determined according to the specific working conditions. Its performance has an important impact on the working efficiency and stability of the hydroturbine. As the SHP-RO system is installed in DSSS and is limited in space, the elbow draft tube shown in Figure 6(d) is more suitable.

4.2. CFD Model for Performance Prediction of Turbine. Based on the 3D fluid domain shown in Figure 6, the geometric model can be established for the CFD modeling. The unstructured tetrahedral grids are adopted for the mesh generation, due to its better adaptability to the complex structure of the turbine. Figure 7 shows the mesh results of the turbine model, in which the runner part is extracted and enlarged for clear sight.

The flow field inside the turbine is usually regarded as incompressible flow and heat exchange in the process can be ignored. The governing equations involved in the simulation include continuity equation and momentum equations, and the turbulence is described by Transition SST model. As to the boundary conditions, the inlet and outlet are set as pressure-inlet and pressure-outlet, respectively. In addition, for the setting of the rotating part, a rotation speed is given for the runner. The runner of the hydraulic turbine,

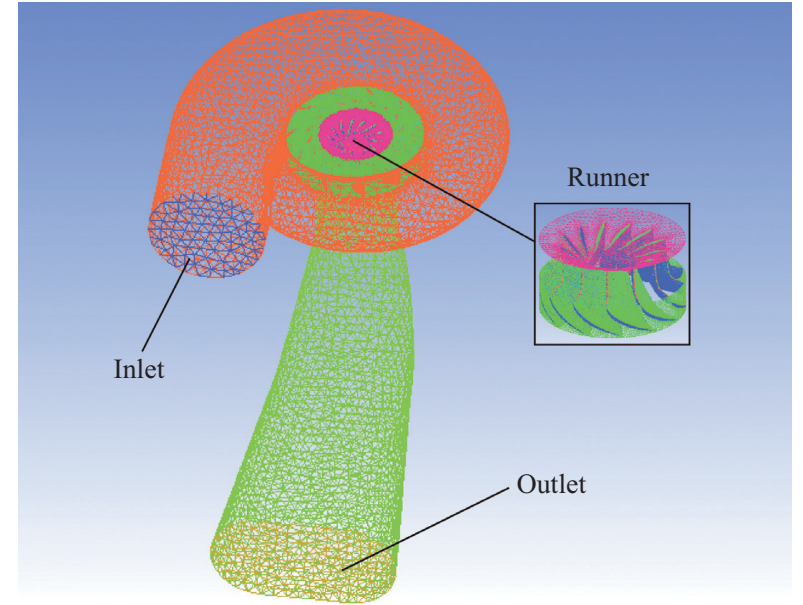

Figure 7: Mesh results of the turbine model.

including blade, upper crown, and lower ring, is defined as moving wall in boundary conditions.

4.3. Simulation Results and Discussion. Based on the numerical simulation of flow behavior in the hydraulic turbine in virtue of the built CFD model, the energy recovery 
TABLE 2: Key parameters sizes of hydraulic turbine.

\begin{tabular}{lccc}
\hline & Cross section of inlet $\left(\mathrm{m}^{2}\right)$ & Diameter of runner $(\mathrm{m})$ & Cross section of outlet $\left(\mathrm{m}^{2}\right)$ \\
\hline Large-size hydraulic turbine & 0.464607 & 0.5 & 0.712651 \\
Small-size hydraulic turbine & 0.004646 & 0.05 & 0.007126 \\
\hline
\end{tabular}

TABLE 3: Inlet and outlet pressure of each stage for different series modes.

\begin{tabular}{lcr}
\hline Stage number & Pressure of inlet $(\mathrm{MPa})$ & Pressure of outlet $(\mathrm{MPa})$ \\
\hline Single-stage series & 5 & 0.101325 \\
\hline \multirow{2}{*}{ Two-stage series } & 5 & 2.5 \\
\hline & 2.5 & 0.101325 \\
Four-stage series & 5 & 3.75 \\
& 3.75 & 2.5 \\
& 2.5 & 1.25 \\
\hline
\end{tabular}

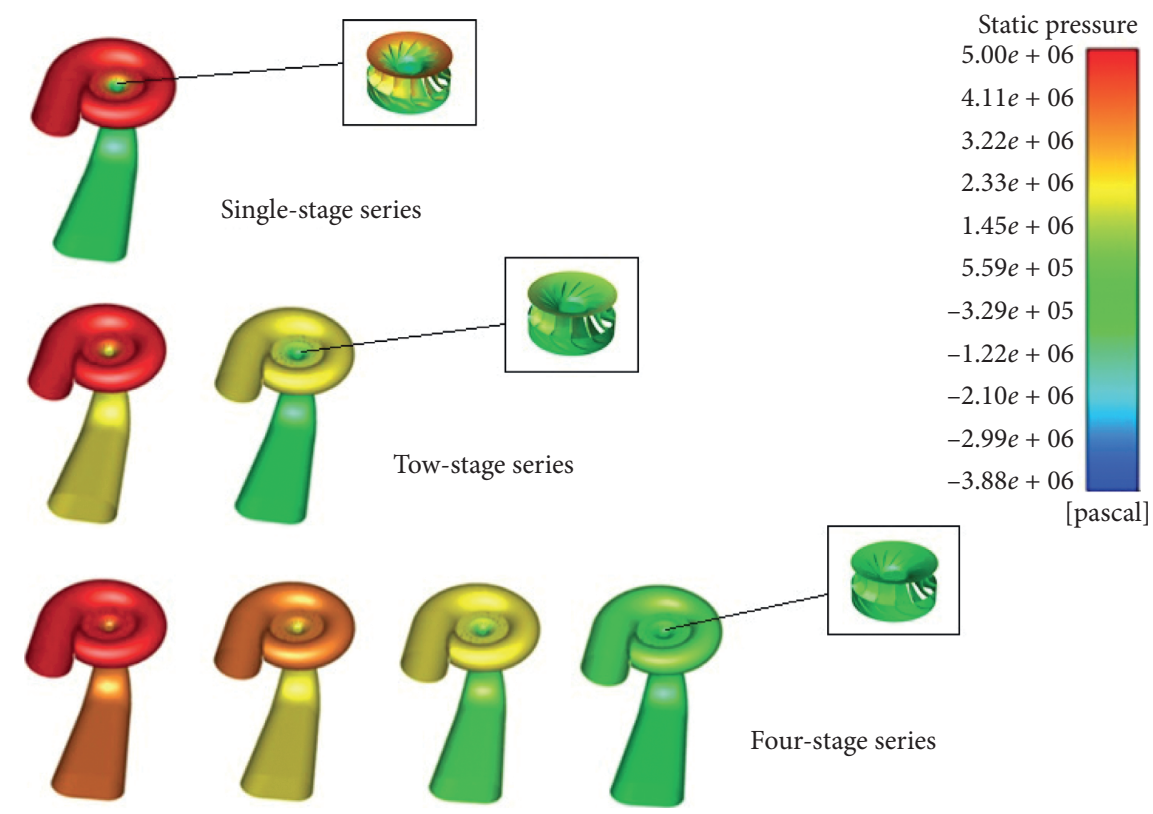

Figure 8: Pressure distribution of different series modes of large-size hydraulic turbine.

performance of the single-stage, the two-stage, and the fourstage series was analyzed. Considering the relationship between the size and the rotating speed of the turbine, two sizes of hydraulic turbine as well as their series modes were investigated. The main parameters of them are shown in Table 2 .

For the series mode, each stage was simulated separately with an even pressure difference in sequence from the back pressure of RO module to the atmospheric pressure, in order to reduce the grid number and shorten the computing time.

4.3.1. Simulation of Large-Size Hydraulic Turbine. For the large-size hydraulic turbine, the diameter of the runner is $500 \mathrm{~mm}$. Supposing that the DSSS locates at the depth of $1100 \mathrm{~m}$, the RO operating pressure drop is $6 \mathrm{MPa}$, and the fresh water production is $10 \mathrm{~m}^{3} / \mathrm{h}$, the residual pressure head to be recovered by hydraulic turbines is from $5 \mathrm{MPa}$ to
$0.1 \mathrm{MPa}$. Table 3 shows the inlet and outlet pressure of each stage for different series modes.

Figure 8 shows the pressure distribution of different series modes of large-size hydraulic turbine. In the one-stage turbine, an obvious and serious cavitation occurs in the runner, possibly resulting in damage to the blades and negative influence for the operation of the turbine, and thus should be avoided in practice. Using two-stage or four-stage mode can effectively alleviate the cavitation, while the complexity and operating difficulty of the system will increase with the stages.

Figures 9-11 show the relationships of output torque, power, and efficiency of large-size turbines with their rotational speed, respectively. The output toque is inversely proportional to the rotational speed of turbines, while the power and efficiency increase initially and then drop down. For the three series modes, the turbine reaches the highest efficiency when the rotational speed achieves $3800 \mathrm{rpm}$, $2600 \mathrm{rpm}$, and $2000 \mathrm{rpm}$, respectively. With the stage 


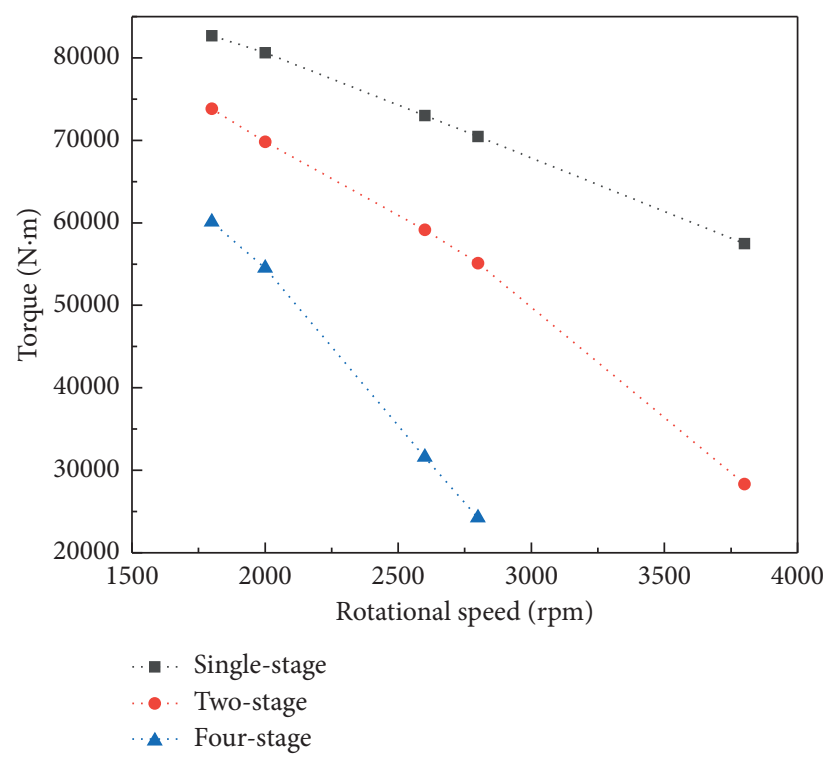

FIGURE 9: Relationship between output torque and rotational speed of large-size turbines.

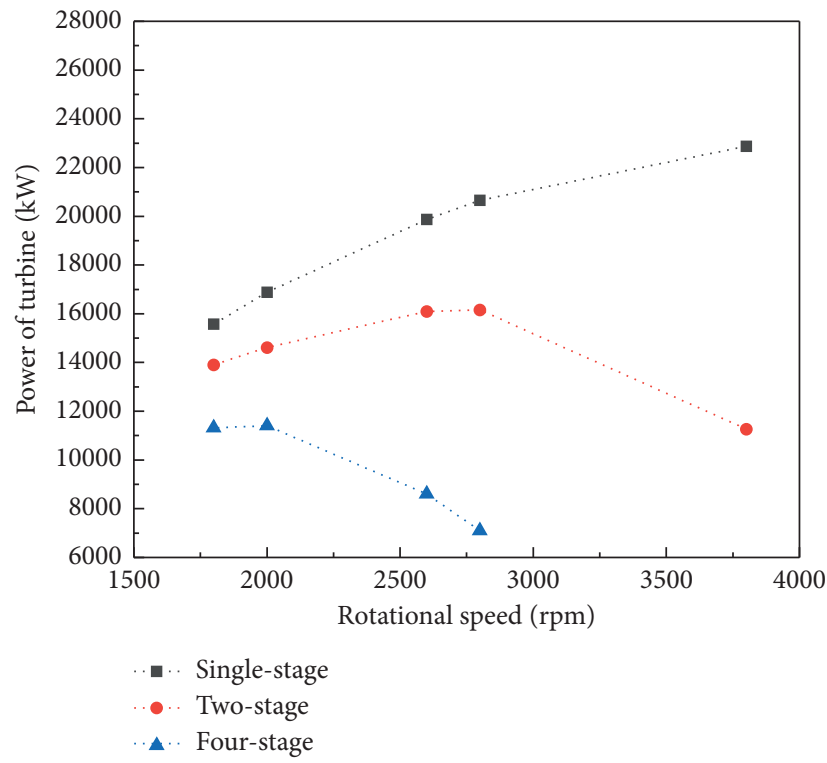

FIGURE 10: Relationship between output power and rotational speed of large-size turbines.

number increase, the output performance degrades. Although the one-stage mode possesses the best output performance, the damage caused by cavitation is the most serious. For the comprehensive consideration, the two-stage series of large-size hydraulic turbine can be an option for the residual pressure energy recovery.

4.3.2. Simulation of Small-Size Hydraulic Turbine. For the small-size hydraulic turbine, the diameter of the runner is $50 \mathrm{~mm}$. The working conditions and boundary conditions of turbines are the same as those of large-size hydraulic turbine. Figure 12 shows the pressure distribution of different series modes of small-size hydraulic turbine, and similar results were obtained to those of the large-size hydraulic turbine.

Figures 13-15 show the relationships of output torque, power, and efficiency of small-size turbines with their rotational speed, respectively. The variation of the output performance with the rotational speed is similar to that of the large-size turbine, i.e., the output torque is inversely proportional to the rotational speed, and the power and efficiency have peak points, but the value differs much except the efficiency. The output torque and power of the large size are 1000 times and 100 times greater than those of the small size, respectively, while the operating rotational speed reduces by about 10 times. The two-stage series exhibits better comprehensive performance too, but the best efficiency 


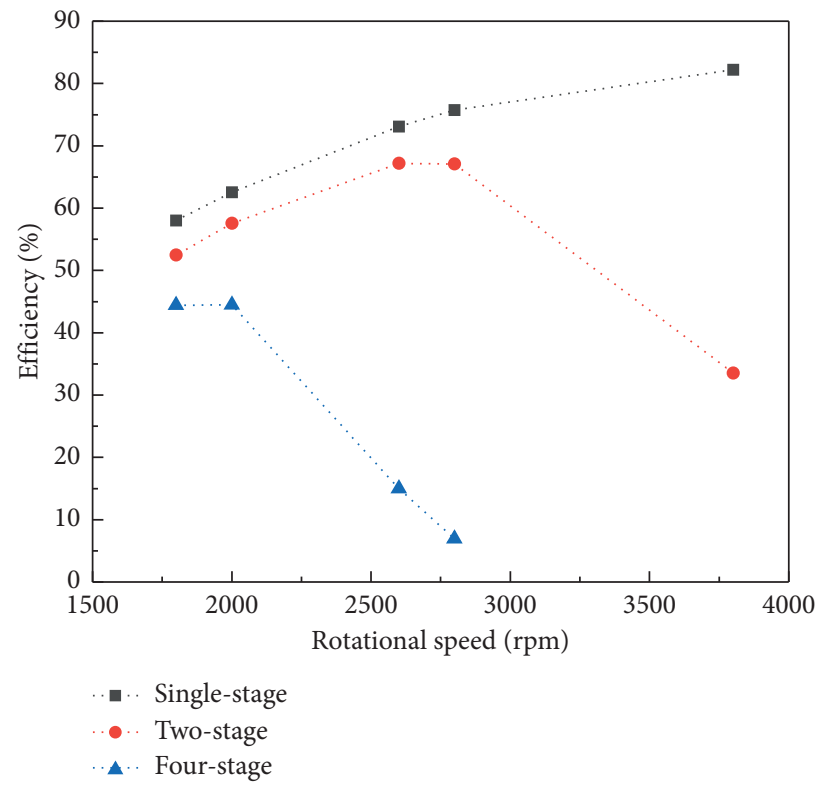

Figure 11: Relationship between output efficiency and rotational speed of large-size turbines.

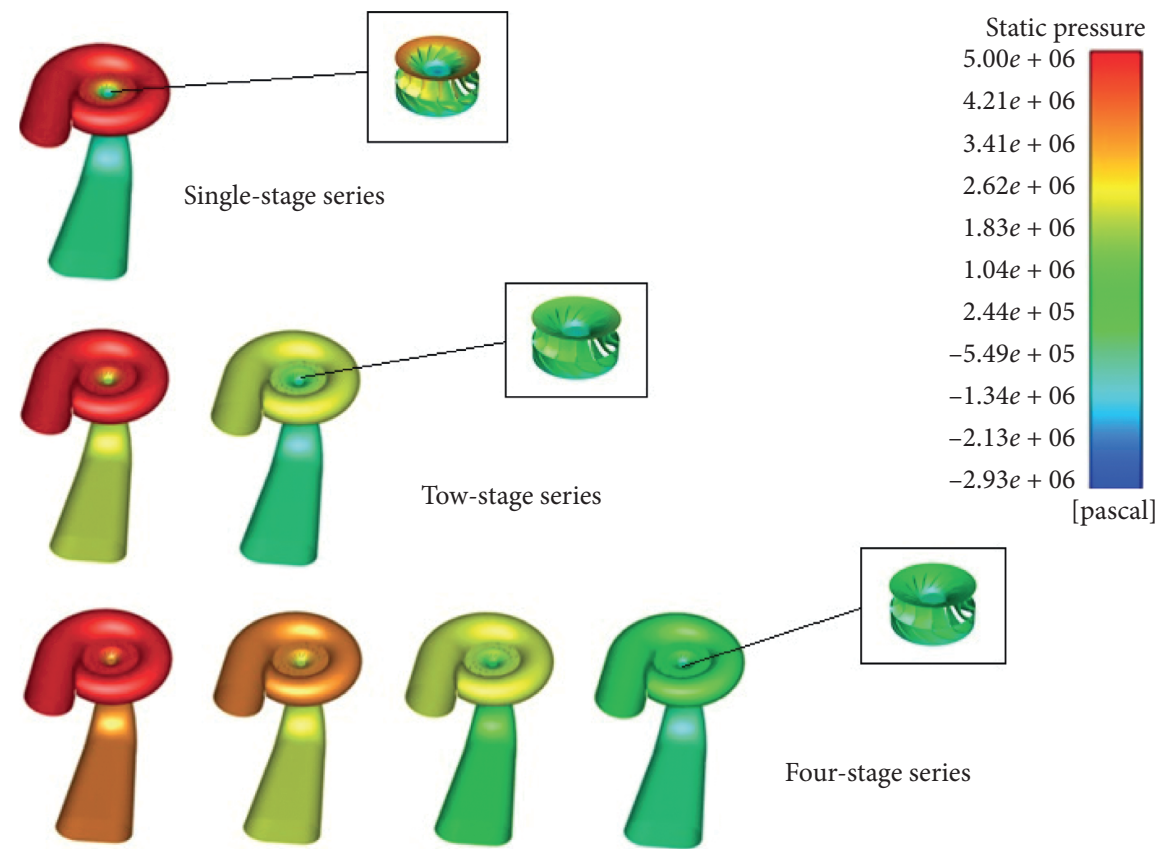

FIGURE 12: Pressure distribution of different series modes of small-size hydraulic turbine.

occurs when the rotational speed achieves near to $30000 \mathrm{rpm}$ which is hardly performed in practice.

4.3.3. Prediction of the Recovered Energy. By analyzing the simulated energy recovery performance of the hydraulic turbines with different size and stage, the two-stage large-size series is considered as the energy recovery module under the above depth condition and water demand. For the energy recovery system, the electricity generation of hydroelectric generator is related to time, efficiency, and power, which is also an important factor to judge the performance of the system.

Since the water production of the described system is $10 \mathrm{~m}^{3} / \mathrm{h}$, a fresh water tank with a volume of $10 \mathrm{~m}^{3}$ is installed before the hydraulic turbine to store the desalinated water produced by $\mathrm{RO}$ membrane. When the $\mathrm{RO}$ desalination system is working, fresh water continuously flows into the freshwater tank. When the storage tank is full, the desalinated 


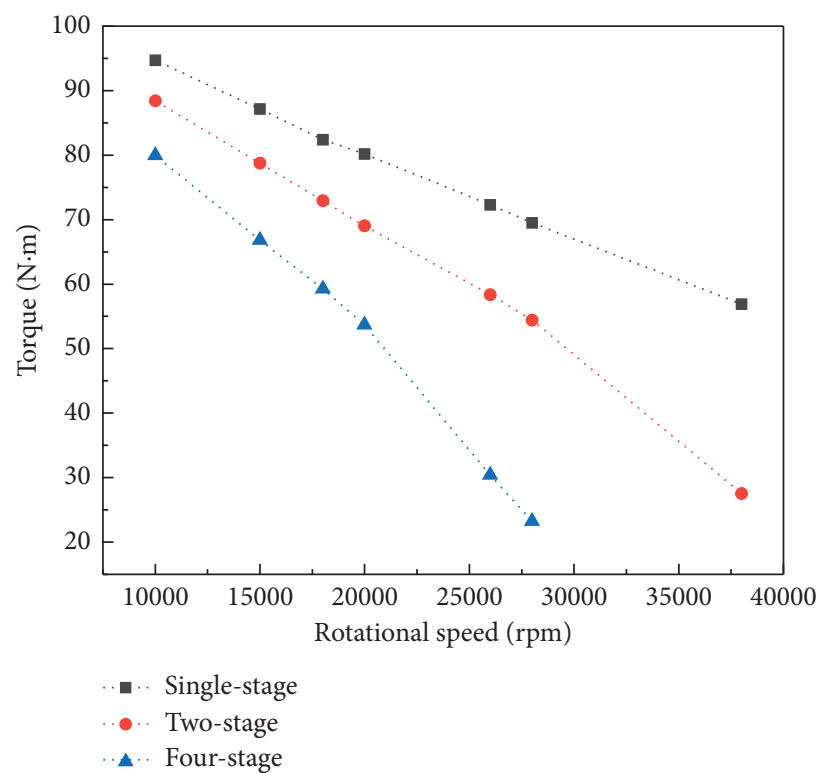

FIGURE 13: Relationship between output torque and rotational speed of small-size turbines.

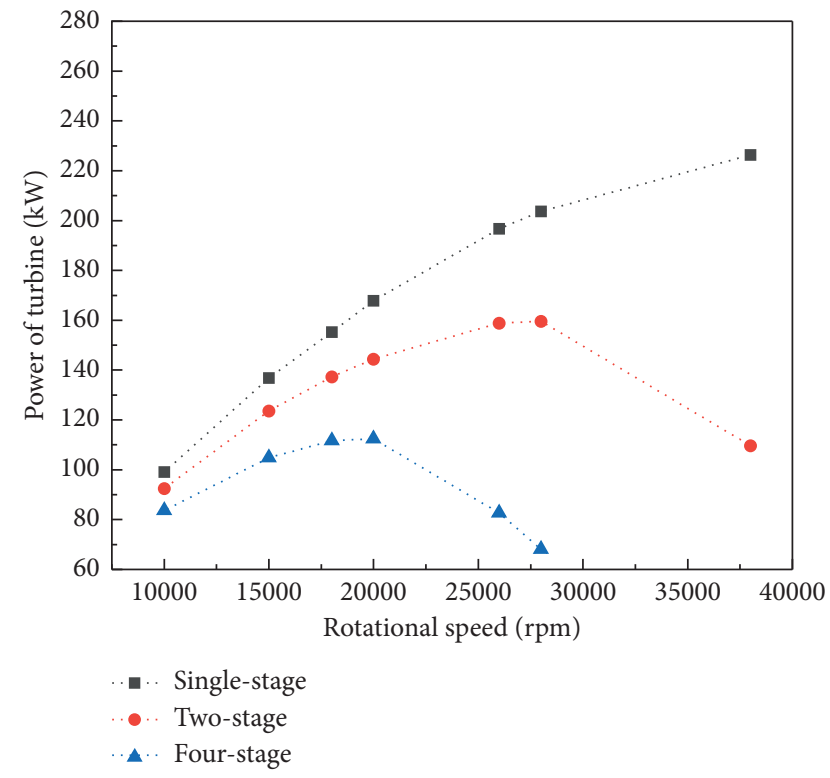

FIGURE 14: Relationship between output power and rotational speed of small-size turbines.

water stored in tank begins to discharge water. The fresh water flows into the turbine to drive the hydro-generator to work and the energy conversion is completed in this process. Figure 16 shows the relationship between the output power and time during discharging and Table 4 shows the working mode of the hydraulic turbines and their pressure settings.

Since the inlet flow rate of the water storage tank is relatively small compared to the outlet flow rate, the pressure in the water storage tank will decrease gradually during the water discharging. The discharging time for each pressure drop of $0.5 \mathrm{MPa}$ is calculated, until the pressure in the water storage tank drops to $0.5 \mathrm{MPa}$. Then, the total discharging time is obtained and the total output electricity of the stored

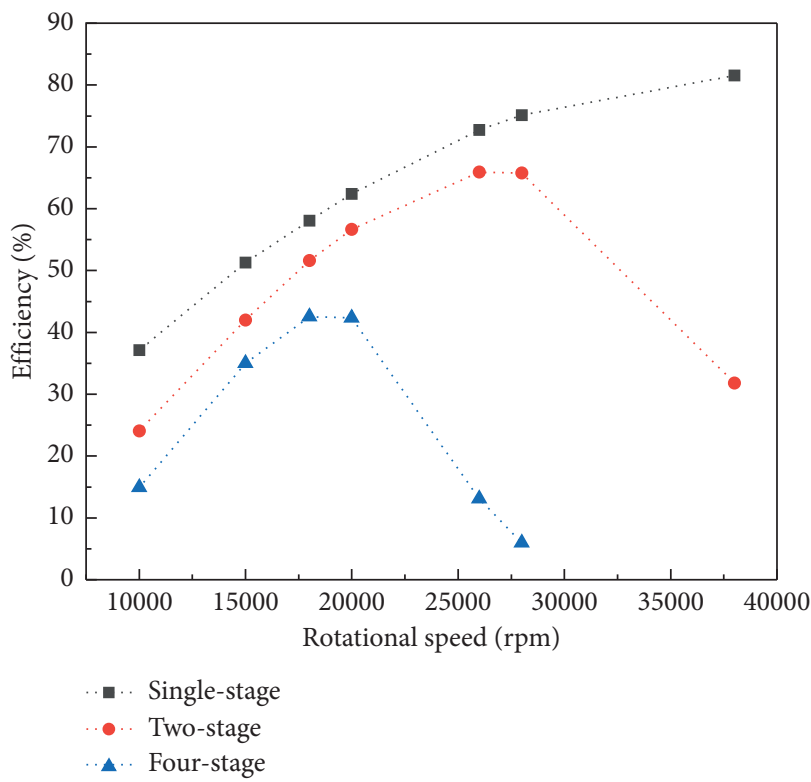

FIGURE 15: Relationship between output efficiency and rotational speed of small-size turbines.

fresh water can be predicted based on the difference principle. When the pressure in the storage tank drops to $0.5 \mathrm{MPa}$, hydroturbine generators stop to work. For the daily water production of $240 \mathrm{~m}^{3}$, the electricity generated by energy recovery device is about $39.22 \mathrm{~kW} \cdot \mathrm{h}$ which is sufficient for the energy consuming devices including the seawater pumps and the control modules, while the major energy consuming process, the RO desalination, is driven by the high hydraulic energy. Thus, the SHP-RO system can fulfill the desalination absolutely by the renewable hydraulic pressure of deep seawater. 


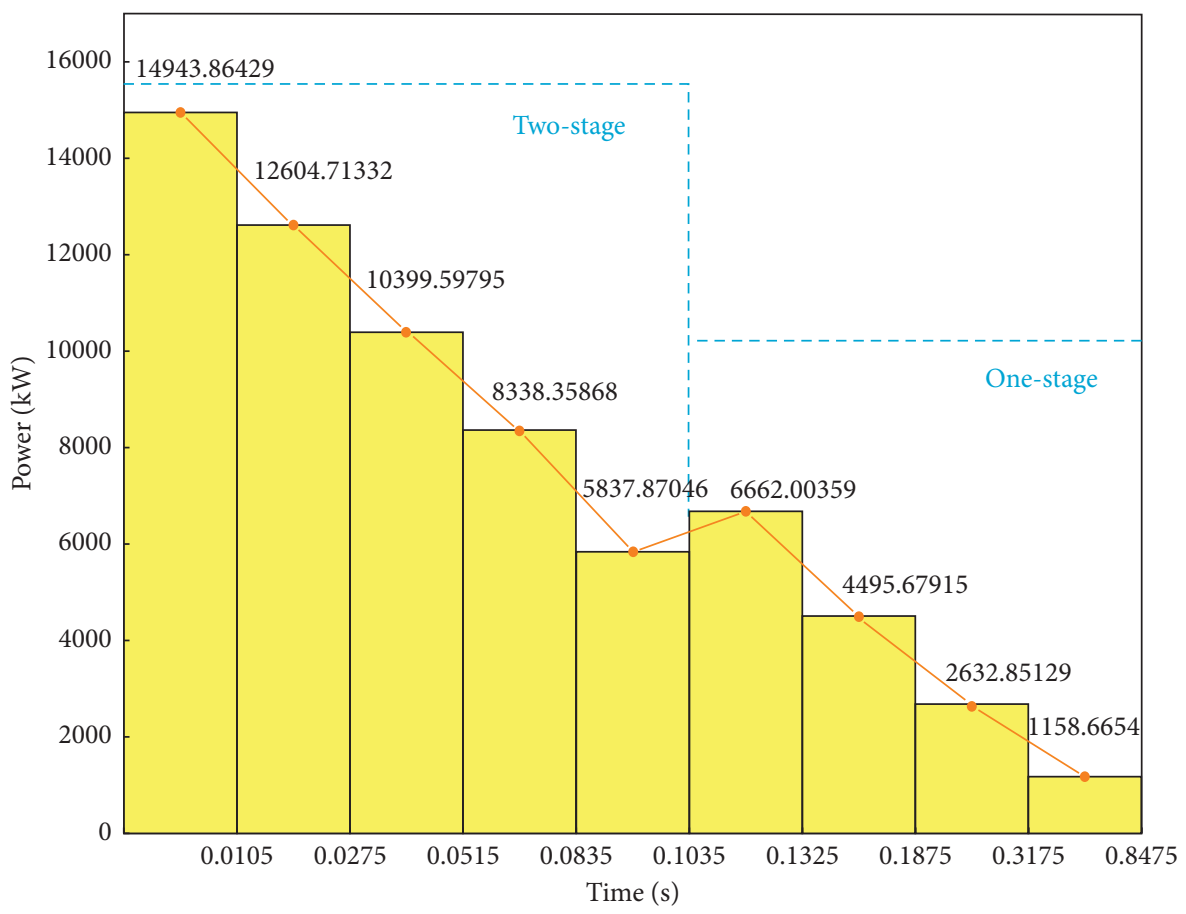

Figure 16: Relationship between power and time during water discharging.

TABLE 4: The setting of pressure relief parameters.

\begin{tabular}{|c|c|c|c|c|}
\hline Stage number & $\begin{array}{l}\text { Pressure in the water storage } \\
(\mathrm{MPa})\end{array}$ & $\begin{array}{l}\text { Inlet pressure of the first stage } \\
(\mathrm{MPa})\end{array}$ & $\begin{array}{l}\text { Inlet pressure of the second stage } \\
(\mathrm{MPa})\end{array}$ & Pressure of outlet \\
\hline \multirow{5}{*}{$\begin{array}{l}\text { Two-stage } \\
\text { series }\end{array}$} & 5 & 2.5 & 2.5 & $\begin{array}{c}\text { Atmospheric } \\
\text { pressure }\end{array}$ \\
\hline & 4.5 & 2.25 & 2.25 & $\begin{array}{l}\text { Atmospheric } \\
\text { pressure }\end{array}$ \\
\hline & 4 & 2 & 2 & $\begin{array}{l}\text { Atmospheric } \\
\text { pressure }\end{array}$ \\
\hline & 3.5 & 1.75 & 1.75 & $\begin{array}{l}\text { Atmospheric } \\
\text { pressure }\end{array}$ \\
\hline & 3 & 1.5 & 1.5 & $\begin{array}{l}\text { Atmospheric } \\
\text { pressure }\end{array}$ \\
\hline \multirow{5}{*}{$\begin{array}{l}\text { Single-stage } \\
\text { series }\end{array}$} & 2.5 & 2.5 & - & $\begin{array}{c}\text { Atmospheric } \\
\text { pressure }\end{array}$ \\
\hline & 2 & 2 & - & $\begin{array}{l}\text { Atmospheric } \\
\text { pressure }\end{array}$ \\
\hline & 1.5 & 1.5 & - & $\begin{array}{l}\text { Atmospheric } \\
\text { pressure }\end{array}$ \\
\hline & 1 & 1 & - & $\begin{array}{c}\text { Atmospheric } \\
\text { pressure }\end{array}$ \\
\hline & 0.5 & 0.5 & - & $\begin{array}{c}\text { Atmospheric } \\
\text { pressure }\end{array}$ \\
\hline
\end{tabular}

\section{Conclusion}

The intermittence, fluctuation, and low energy density are major disadvantages of the common marine renewable energy sources such as solar energy, wind energy, and wave energy, etc., restricting their effective applications in the ocean exploration. Meanwhile, distant and deep sea exploring activities will become increasingly frequent to obtain various ocean resources, and the large-scale Deep Sea Space Station (DSSS) will become popular for long-term stay of mankind in which the fresh water supply is necessary for human survival.

Compared with the common marine renewable energy sources like solar energy, wind energy, and wave energy, etc., the hydraulic pressure energy stored in the deep seawater can output stable and successive energy flow. It can provide 
an environment friendly and energy saving solution for the water demand of large-scale DSSS by coupling with the RO process, generating drinkable water from the clean and nutritious deep seawater. For this reason, we proposed a submarine RO system driven by the hydraulic pressure of deep seawater (SHP-RO) which was composed of a desalination branch to generate fresh water and a back pressure branch to ensure the depth independence of the desalination process. The influences of the deep sea environment on the desalination performance were analyzed, and the permeate flux loss caused by the temperature decrease was suggested to be compensated by enlarging the membrane area and increasing the operating pressure within the operating limit and the depth limit. Due to the cleanness of the deep seawater and the environmental requirement of the deep sea exploration, the pretreatment was composed of series of membrane modules and chemical reagent free. The mineral drinkable water was finally generated by mixing the desalinated water and the deep seawater in a certain proportion which was determined according to the standard for drinking water by WHO.

To recover the residual hydraulic energy of desalinated water and avoid its shock and damage to the system, several turbines were installed in the freshwater branch after the energy-water storage tank. The energy recovery performance of different series mode of Francis turbines was investigated in virtue of the CFD simulation, based on which a turbinebased scheme for the prediction of energy recovery was investigated. At enough depth and with enough water production rate, hydraulic pressure energy of the deep seawater can not only drive the $\mathrm{RO}$ process, but also meet all the energy demand of the whole SHP-RO system with the pumps and control modules driven by the recovered energy.

Different with the submarine desalination system mentioned in the literatures, all the equipment of the SHP-RO system can be integrated in the DSSS, refraining from the technical difficulties in design and operation, such as coupling difficulty between offshore platform and undersea devices and pipes, installation and maintenance difficulties, etc. Therefore, with the increasingly DSSS applications in the future, the SHP-RO technique will play a more and more important role.

\section{Data Availability}

The data used to support the findings of this study are included within the article.

\section{Conflicts of Interest}

The authors declare no conflicts of interest.

\section{Authors' Contributions}

Yifan Cui and Lu Hui contributed equally to the work.

\section{Acknowledgments}

This research was funded by the National Natural Science Foundations of China (51769006).

\section{References}

[1] Anonymous, Millennium Development Goals Report, United Nations, New York, NY, USA, 2008.

[2] K. H. Al-Zahrani, "Water demand management in the Kingdom of Saudi Arabia," International Journal of Arts and Sciences, vol. 2, pp. 68-76, 2010.

[3] A. D. Khawaji, I. K. Kutubkhanah, and J.-M. Wie, "Advances in seawater desalination technologies," Desalination, vol. 221, no. 1-3, pp. 47-69, 2008.

[4] M. M. Aboelmaaref, M. E. Zayed, J. Zhao et al., "Hybrid solar desalination systems driven by parabolic trough and parabolic dish CSP technologies: technology categorization, thermodynamic performance and economical assessment," Energy Conversion and Management, vol. 220, no. 15, p. 113103, 2020.

[5] N. A. Ahmad, P. S. Goh, L. T. Yogarathinam, A. K. Zulhairun, and A. F. Ismail, "Current advances in membrane technologies for produced water desalination," Desalination, vol. 493, p. 114643, 2020.

[6] K. Elsaid, E. T. Sayed, M. A. Abdelkareem, M. S. Mahmoud, M. Ramadan, and A. Olabi, "Environmental impact of emerging desalination technologies: a preliminary evaluation," Journal of Environmental Chemical Engineering, vol. 8, no. 5, p. 104099, 2020.

[7] A. Mollahosseini, A. Abdelrasoul, S. Sheibany, M. Amini, and S. K. Salestan, "Renewable energy-driven desalination opportunities - a case study," Journal of Environmental Management, vol. 239, pp. 187-197, 2019.

[8] M. A. M. Khan, S. Rehman, and F. A. Al-Sulaiman, "A hybrid renewable energy system as a potential energy source for water desalination using reverse osmosis: a review," Renewable and Sustainable Energy Reviews, vol. 97, pp. 456-477, 2018.

[9] Q. Zhang, S. Chen, Z. Fu, H. Yu, and X. Quan, “Temperaturedifference-induced electricity during solar desalination with bilayer MXene-based monoliths," Nano Energy, vol. 76, p. $105060,2020$.

[10] A. M. Delgado-Torres, L. García-Rodríguez, and M. J. Del Moral, "Preliminary assessment of innovative seawater reverse osmosis (SWRO) desalination powered by a hybrid solar photovoltaic (PV) - tidal range energy system," Desalination, vol. 477, p. 114247, 2020.

[11] L. Fernández Prieto, G. Rodríguez Rodríguez, and J. Schallenberg Rodríguez, "Wave energy to power a desalination plant in the north of Gran Canaria Island: wave resource, socioeconomic and environmental assessment," Journal of Environmental Management, vol. 231, pp. 546-551, 2019.

[12] Q. Ma and H. Lu, "Wind energy technologies integrated with desalination systems: review and state-of-the-art," Desalination, vol. 277, no. 1-3, pp. 274-280, 2011.

[13] W. Lai, Q. Ma, H. Lu, S. Weng, J. Fan, and H. Fang, "Effects of wind intermittence and fluctuation on reverse osmosis desalination process and solution strategies," Desalination, vol. 395, pp. 17-27, 2016.

[14] C. Charcosset, C. Falconet, and M. Combe, "Hydrostatic pressure plants for desalination via reverse osmosis," Renewable Energy, vol. 34, no. 12, pp. 2878-2882, 2009.

[15] D. Colombo, M. De Gerloni, and M. Reali, "An energy-efficient submarine desalination plant," Desalination, vol. 122, no. 2-3, pp. 171-176, 1999.

[16] P. Pacenti, M. De Gerloni, M. Reali et al., "Submarine seawater reverse osmosis desalination system," Desalination, vol. 126, no. 1-3, pp. 213-218, 1999. 
[17] P. Pacenti, M. Reali, N. Brambilla et al., "Deployment of a submarine reverse osmosis desalination prototype plant (RODSS): field tests and preliminary technical evaluations," Desalination, vol. 138, no. 1-3, p. 181, 2001.

[18] M. Reali, M. De Gerloni, and A. Sampaolo, "Submarine and underground reverse osmosis schemes for energy-efficient seawater desalination," Desalination, vol. 109, no. 3, pp. 269-275, 1997.

[19] S. Al-Kharabsheh, "An innovative reverse osmosis desalination system using hydrostatic pressure," Desalination, vol. 196, no. 1-3, pp. 210-214, 2006.

[20] NASA, About Aquarius, NASA, Washington, D.C., USA, 2006, https://www.nasa.gov/mission_pages/NEEMO/ facilities.html.

[21] I.-S. Chen, Y.-Y. Chang, C.-L. Hsu et al., "Alleviative effects of deep-seawater drinking water on hepatic lipid accumulation and oxidation induced by a high-fat diet," Journal of the Chinese Medical Association, vol. 76, no. 2, pp. 95-101, 2013.

[22] M. Miyamura, S. Yoshioka, A. Hamada et al., "Difference between deep seawater and surface seawater in the preventive effect of atherosclerosis," Biological \& Pharmaceutical Bulletin, vol. 27, no. 11, pp. 1784-1787, 2004.

[23] S.-I. Katsuda, T. Yasukawa, K. Nakagawa et al., "Deep-Sea water improves cardiovascular hemodynamics in Kurosawa and Kusanagi-hypercholesterolemic (KHC) rabbits," Biological \& Pharmaceutical Bulletin, vol. 31, no. 1, pp. 38-44, 2008.

[24] M.-H. Chang, B.-S. Tzang, T.-Y. Yang, Y.-C. Hsiao, H.-C. Yang, and Y.-C. Chen, "Effects of deep-seawater on blood lipids and pressure in high-cholesterol dietary mice," Journal of Food Biochemistry, vol. 35, no. 1, pp. 241-259, 2011.

[25] B. Ha, E. Shin, J.-E. Park, and Y. Shon, "Anti-diabetic effect of balanced deep-sea water and its mode of action in high-fat diet induced diabetic mice," Marine Drugs, vol. 11, no. 11, pp. 4193-4212, 2013.

[26] S. Z. Mohd Nani, F. A. A. Majid, A. B. Jaafar, A. Mahdzir, and M. N. Musa, "Potential health benefits of deep sea water: a review," Evidence-Based Complementary and Alternative Medicine, vol. 2016, 2016.

[27] K.-S. Lee, Y.-S. Kwon, S. Kim, D.-S. Moon, H. J. Kim, and K.-S. Nam, "Regulatory mechanism of mineral-balanced deep sea water on hypocholesterolemic effects in HepG2 hepatic cells," Biomedicine \& Pharmacotherapy, vol. 86, pp. 405-413, 2017.

[28] K.-S. Lee, S.-Y. Chun, M.-G. Lee, S. Kim, T.-J. Jang, and K.-S. Nam, "The prevention of TNF- $\alpha /$ IFN- $\gamma$ mixture-induced inflammation in human keratinocyte and atopic dermatitis-like skin lesions in $\mathrm{Nc} / \mathrm{Nga}$ mice by mineral-balanced deep sea water," Biomedicine \& Pharmacotherapy, vol. 97, pp. 1331-1340, 2018.

[29] P. C. Chu, C. R. Fralick, S. D. Haeger, and M. J. Carron, "A parametric model for the yellow sea thermal variability," Journal of Geophysical Research: Oceans, vol. 102, no. C5, pp. 10499-10507, 1997.

[30] P. C. Chu, C. Fan, and W. T. Liu, "Determination of vertical thermal structure from sea surface temperature," Journal of Atmospheric and Oceanic Technology, vol. 17, no. 7, pp. 971979, 2000.

[31] Q. F. Alsalhy, T. M. Albyati, and M. A. Zablouk, "A study of the effect of operating conditions on reverse osmosis membrane performance with and without air sparging technique," Chemical Engineering Communications, vol. 200, no. 1, pp. 1-19, 2013.
[32] S. He, H. Liu, X. Yang, C. Li, and H. Guan, "What depth should deep-sea water be pumped up from in the South China Sea for medicinal research?" Journal of Ocean University of China, vol. 12, no. 1, pp. 134-138, 2013. 